\title{
Analisis Biaya Dan Permintaan Dalam Penetapan Harga Pokok Penjualan Unit Apartemen Puncak Darmahusada
}

\author{
Maulidul Rahman dan Christiono Utomo \\ Jurusan Teknik Sipil, Fakultas Teknik Sipil dan Perencanaan, Institut Teknologi Sepuluh Nopember (ITS) \\ Jl. Arief Rahman Hakim, Surabaya 60111 Indonesia \\ E-mail: christiono@ce.its.ac.id
}

\begin{abstract}
Abstrak-Apartemen Puncak Dharmahusada berlokasi di jalan Ir. Soekarno, MERR, Surabaya Timur. Ada beberapa apartemen sejenis seperti, Apartemen Puncak Kertajaya, Apartemen Cosmopolis, Apartemen Gunawangsa dll. dengan kisaran harga dan jenis fasilitas relatif sama. Untuk itu perlu adanya suatu analisa dalam menentukan berapa harga pokok penjualan unit agar apartemen Puncak Dharmahusada dapat bersaing dengan baik di pasar. Penetapan harga jual dilakukan dengan analisa pendekatan biaya yang menghasilkan kurva biaya, analisa pendekatan permintaan yang menghasilkan kurva permintaan, dan analisa pendekatan marginal. Berdasarkan metode pendekatan marginal didapatkan harga jual tiap tipe, yaitu; tipe 1 BR Rp 295,619,109.56,-, tipe 2 BR Rp 423,945,303.77,-, dan tipe 3 BR Rp 661,890,423.79,-.
\end{abstract}

Kata Kunci-apartemen, harga, kurva biaya, kurva permintaan, pendekatan marginal.

$\mathrm{P}$ ENINGKATAN jumlah penduduk di perkotaan diproyeksikan akan terus meningkat. Surabaya sebagai kota kedua terbesar setelah Jakarta telah mengalami masalah tersebut. Peningkatan jumlah penduduk setiap tahunnya dikarenakan oleh berbagai faktor di antaranya adalah urbanisasi (perpindahan penduduk dari desa ke kota) dan fertilisasi (kelahiran).

Dengan tingkat pertumbuhan penduduk sebanyak $1.2 \%$ tentu saja akan mengakibatkan kebutuhan tempat tinggal yang layak akan sangat besar. Kebutuhan yang besar tersebut akan berimplikasi pada penggunaan lahan kosong yang seharusnya dimanfaatkan sebagai paru-paru kota seperti Ruang Terbuka Hijau (RTH). Sementara itu ketersediaan lahan di Surabaya cenderung tetap dan terbatas. Untuk itu diperlukan solusi bangunan tempat tinggal yang bisa menampung penghuni yang besar sementara lahan yang dibutuhkan relatif kecil. Salah satu alternatif untuk masalah ini adalah apartemen.

Saat ini pertumbuhan apartemen di Surabaya semakin pesat, para pengembang properti berlomba-lomba membangun apartemen, salah satunya apartemen Puncak Dharmahusada. Apartemen Puncak Dharmahusada berlokasi di jalan Ir. Soekarno, MERR, Surabaya Timur. Apartemen ini mempunyai konsep one stop living yang artinya semua kebutuhan tersedia di dalam apartemen ini, seperti fasilitas olahraga, pusat perbelanjaan, are $\mathrm{BBQ}$, dan juga dilengkapi dengan sistem pengamanan yang beroperasi selama 24 jam setiap harinya. Apartemen ini menawarkan beberapa tipe hunian, yaitu tipe 1 BR, 2 BR, 3 BR, dan 4 BR, dengan masing-masing harga Rp. 295.000.000,00, Rp. 424.500.000,00, Rp. 600.000. 000,00.

Ada beberapa apartemen sejenis seperti, Apartemen Puncak Kertajaya, Apartemen Cosmopolis, Apartemen Gunawangsa dll. Dengan kisaran harga dan jenis fasilitas relatif sama. Untuk itu perlu adanya suatu analisa dalam menentukan berapa harga pokok penjualan unit agar apartemen Puncak Dharmahusada dapat bersaing dengan baik di pasar.

\section{PENELITIAN TERDAHULU}

Aprilia dan Utomo [1] meneliti tentang penetapan harga jual unit apartemen Bale Hinggil di Surabaya. Tujuan penelitian ini adalah mendapatkan harga jual dengan pendekatan biaya yang menghasilkan kurva biaya, pendekatan permintaan dengan kuesioner yang menghasilkan kurva permintaan dan pendekatan marginal.

Hanundyasari dan Utomo [2], meneliti tentang harga pokok penjualan apartemen Puri Park View Tower E Kebon JerukJakarta Barat. Tujuan penelitian tersebut untuk mendapatkan harga pokok jual dengan dua skenario harga yaitu menggunakan pembebanan biaya komersil dan tanpa pembebanan biaya komersil. Dalam analisis digunakan metode break even point pada margin keuntungan yang direncanakan.

Hidayat dan Utomo [3] meneliti tentang harga jual unit rumah di perumahan Griya Agung Permata, Lamongan dengan analisa titik impas yang mempertemukan kurva biaya dan kurva pendapatan.

Fahad dan Utomo [4], meneliti tentang analisa penetapan harga jual unit rumah pada proyek perumahan Soka Park Bangkalan. Penelitian ini dilakukan dengan metode analisa titik impas analisa biaya dan permintaan pasar.

Damayanti dan Utomo [5], meneliti tentang analisa biaya dan permintaan pada penetapan harga marginal unit rumah di perumahan Royal Regency, Lumajang. Penelitian ini menggunakan metode harga marginal dengan mempertemukan kurva biaya dan permintaan

Wahyudi dan Utomo [6], meneliti tentang analisa investasi pada proyek pembangunan apartemen Bale Hinggil Surabaya. 
Penelitian ini bertujuan untuk mendapatkan alternatif pendapatan yang optimal dari pemilihan alternatif pendapatan antara apartemen sewa, apartemen jual dan gabungan keduanya.

\section{METODOLOGI}

\section{A. Tahapan Penelitian}

Tahap penelitian disajikan pada Gambar 1.

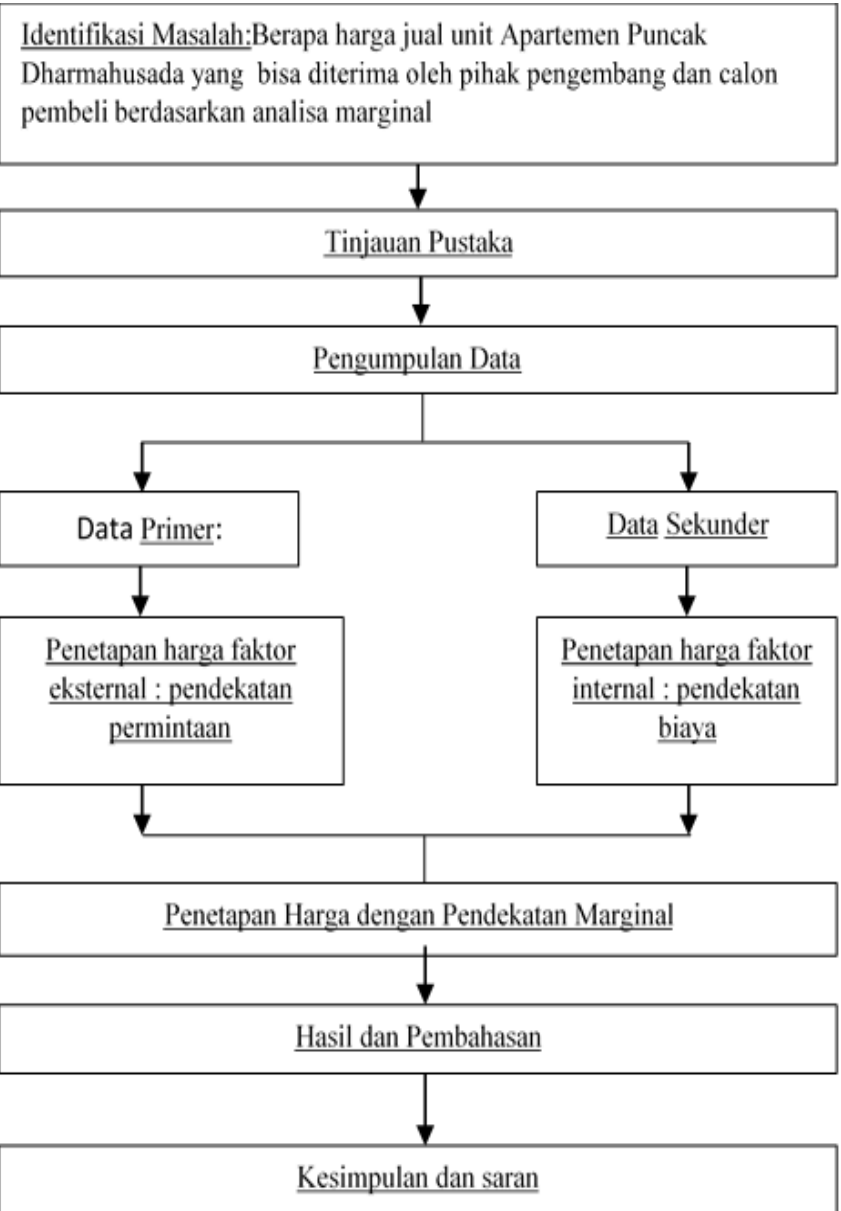

Gambar 1. Diagram Alir Penelitian

\section{B. Data}

Dalam penulisan tugas akhir ini digunakan dua jenis data; yaitu data primer data sekunder. Data primer diperoleh melalui wawancara dengan pihak pengembang, observasi lapangan, dan riset survei dengan kuesioner terhadap calon pembeli. Data sekunder diperoleh melalui brosur promosi dari pihak pengembang.

\section{Analisis Pendekatan Biaya}

Biaya perusahaan dan produk menetapkan harga batas bawah yang dapat dikenakan perusahaan agar perusahaan tidak mengalami kerugian. Biaya dibagi menjadi biaya tetap dan biaya variabel; biaya tetap tidak berubah mengikuti jumlah unit output, biaya variabel berubah sesuai unit output. Biaya total (TC) adalah penjumlahan dari biaya variabel total (TVC) dan biaya tetap total (TFC). Biaya total rata-rata (ATC) adalah biaya produksi yang dibebankan untuk setiap unit output [7].
Setelah diketahui persamaan TFC, TVC, dan TC, dapat dibentuk kurva biaya. Kurva tersebut menunjukkan perbandingan antara jumlah produksi dengan besarnya biaya yang dibutuhkan dalam pembuatan produk [7].

\section{Analisis Pendekatan Permintaan}

Nilai dari pembeli merupakan batas atas yang dapat dikenakan perusahaan agar dapat menarik permintaan. Penetapan harga dimulai dengan menganalisis kebutuhan pembeli dan persepsi mereka, dan kemudian ditetapkan harga produk untuk menyamakan nilai anggapan pembeli [7]. Untuk mendapatkan nilai dari pelanggan, digunakan riset survei dengan metode kuesioner terhadap tiga puluh responden, sampel yang digunakan yaitu calon pembeli potensial.

Kuesioner berisi pertanyaan kesediaan pembeli pada unit apartemen dengan tingkatan harga yang bervariasi. Kurva permintaan dapat dibentuk dengan membandingkan jumlah unit yang diminta dengan tingkatan harga yang ditawarkan. Dengan demikian dapat diketahui persamaan harga $(\mathrm{P})$ yang dapat diterima oleh pasar [8].

\section{E. Analisis Pendekatan Marginal}

Biaya marginal (marginal cost) adalah pertambahan atau pengurangan biaya total karena bertambahnya atau berkurangnya satu unit output, biaya marginal menurun sejalan dengan meningkatnya volume produksi [9].

MC merupakan penurunan biaya total (TC) terhadap unit output (Q). Penerimaan marginal (marginal revenue) adalah kenaikan atau penurunan penerimaan sebagai akibat dari penambahan atau pengurangan satu unit output [9]. MR merupakan penurunan penerimaan total (TR) terhadap unit output (Q). Kondisi yang diharapkan perusahaan adalah saat biaya marginal sama dengan penerimaan marginal $(\mathrm{MC}=\mathrm{MR})$.

\section{HASIL DAN PEMBAHASAN}

Apartemen puncak dharmahusada menawarkan 3 tipe hunian, berikut ini dalam Tabel 1 data-data terkait:

Tabel 1.

Data Unit Apartemen

\begin{tabular}{cccc}
\hline \hline Data Unit & \multicolumn{3}{c}{ Tipe Unit } \\
& 1 BR & 2 BR & 3 BR \\
\hline Luas Unit $\left(\mathrm{m}^{2}\right)$ & 38.125 & 49.105 & 84.6 \\
Jumlah unit & 96 & 512 & 192 \\
\hline \hline
\end{tabular}

Sumber : Data Olahan Penulis

\section{A. Analisis Pendekatan Biaya}

Metode pendekatan biaya berguna untuk menentukan besarnya biaya yang dikeluarkan untuk memproduksi unit output. Dalam penetapan biaya total, perlu diidentifikasi biaya yang termasuk dalam biaya tetap dan biaya variabel.

Biaya investasi dianggap sebagai biaya tetap (Fixed Cost), biaya operasional dan karyawan, merupakan biaya tidak tetap (Variable Cost) [10]. Biaya tetap meliputi biaya bangunan, biaya perlengkapan bangunan, biaya pengembangan tapak, biaya administrasi, biaya pembelian lahan, biaya jasa profesi, dan biaya tak terduga. 
Semua perhitung mengenai biaya-biaya dalam pembangunan proyek ini, dilakukan pendekatan secara empiris [10]. Berikut ini rekapitulasi biaya tetap yang ditampilkan dalam Tabel 2.

Tabel 2.

Biaya Tetap

\begin{tabular}{clr}
\hline \hline No. & Uraian & \multicolumn{1}{c}{ Biaya (Rp.) } \\
\hline 1 & Biaya Bangunan & $173,780,989,237.80$ \\
2 & Biaya Perlengkapan Bangunan & $83,951,415,600.00$ \\
3 & Biaya Administrasi & $3,475,619,784.76$ \\
4 & Pembelian Lahan & $28,000,000,000.00$ \\
5 & Jasa Profesi & $10,426,859,354.27$ \\
6 & Tak Terduga & $26,067,148,385.67$ \\
& Total & $325,702,032,362.49$ \\
\hline \hline
\end{tabular}

Sumber : Data Olahan Penulis

Biaya variabel adalah biaya yang bertambah besar seiring dengan bertambahnya jumlah unit output. Dalam proyek apartemen ini biaya variabel adalah biaya operasional. Berikut ini rekapitulasi biaya variabel pada Tabel 3 .

Tabel 3.

Biaya variabel

\begin{tabular}{llr}
\hline \hline No. & \multicolumn{1}{c}{ Jenis Pekerjaan } & Biaya (Rp) \\
\hline 1 & Biaya Pemasaran & $1,603,500,000$ \\
2 & Listrik & $176,973,984$ \\
3 & Air & $3,421,440$ \\
4 & Gaji Pegawai Kantor & 2304000000 \\
& Total & $4,087,895,424$ \\
\hline \hline
\end{tabular}

Sumber : Data Olahan Penulis

Biaya total adalah hasil penjumlahan dari biaya tetap total dengan biaya variabel total. Berdasarkan perhitungan biaya tetap dan biaya variabel, rekapitulasi biaya total dalam Tabel 4 dan Kurva Biaya Total pada Gambar 2.

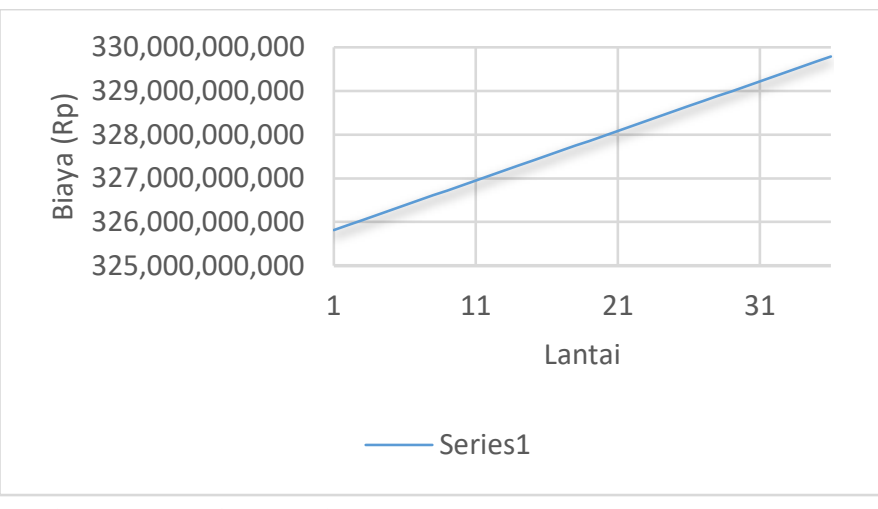

Gambar 2. Kurva Biaya Total

\section{B. Analisis Pendekatan Permintaan}

Untuk menunjukkan kemungkinan pembelian pasar terhadap suatu barang dalam berbagai variasi tingkatan harga, dapat digunakan kurva permintaan, kurva tersebut menjumlahkan reaksi beberapa individu yang memiliki kepekaan pasar yang beragam [9].
Kurva permintaan dibuat menggunakan data yang dihasilkan dari riset survei yaitu kuesioner, dengan sampel berjumlah 30 orang. Para responden merupakan calon pembeli potensial di lokasi kantor pemasaran Apartemen Puncak Dharmahusada.

Tabel 4.

Biaya Total

\begin{tabular}{|c|c|c|c|}
\hline Lantai & Biaya Tetap & $\begin{array}{c}\text { Biaya variabel } \\
\text { komulatif }\end{array}$ & Biaya Total \\
\hline 1 & $325,702,032,362$ & $113,552,651$ & $325,815,585,013$ \\
\hline 2 & $325,702,032,362$ & $227,105,301$ & $325,929,137,664$ \\
\hline 3 & $325,702,032,362$ & $340,657,952$ & $326,042,690,314$ \\
\hline 4 & $325,702,032,362$ & $454,210,603$ & $326,156,242,965$ \\
\hline 5 & $325,702,032,362$ & $567,763,253$ & $326,269,795,616$ \\
\hline 6 & $325,702,032,362$ & $681,315,904$ & $326,383,348,266$ \\
\hline 7 & $325,702,032,362$ & $794,868,555$ & $326,496,900,917$ \\
\hline 8 & $325,702,032,362$ & $908,421,205$ & $326,610,453,568$ \\
\hline 9 & $325,702,032,362$ & $1,021,973,856$ & $326,724,006,218$ \\
\hline 10 & $325,702,032,362$ & $1,135,526,507$ & $326,837,558,869$ \\
\hline 11 & $325,702,032,362$ & $1,249,079,157$ & $326,951,111,520$ \\
\hline 12 & $325,702,032,362$ & $1,362,631,808$ & $327,064,664,170$ \\
\hline 13 & $325,702,032,362$ & $1,476,184,459$ & $327,178,216,821$ \\
\hline 14 & $325,702,032,362$ & $1,589,737,109$ & $327,291,769,472$ \\
\hline 15 & $325,702,032,362$ & $1,703,289,760$ & $327,405,322,122$ \\
\hline 16 & $325,702,032,362$ & $1,816,842,411$ & $327,518,874,773$ \\
\hline 17 & $325,702,032,362$ & $1,930,395,061$ & $327,632,427,424$ \\
\hline 18 & $325,702,032,362$ & $2,043,947,712$ & $327,745,980,074$ \\
\hline 19 & $325,702,032,362$ & $2,157,500,363$ & $327,859,532,725$ \\
\hline 20 & $325,702,032,362$ & $2,271,053,013$ & $327,973,085,376$ \\
\hline 21 & $325,702,032,362$ & $2,384,605,664$ & $328,086,638,026$ \\
\hline 22 & $325,702,032,362$ & $2,498,158,315$ & $328,200,190,677$ \\
\hline 23 & $325,702,032,362$ & $2,611,710,965$ & $328,313,743,328$ \\
\hline 24 & $325,702,032,362$ & $2,725,263,616$ & $328,427,295,978$ \\
\hline 25 & $325,702,032,362$ & $2,838,816,267$ & $328,540,848,629$ \\
\hline 26 & $325,702,032,362$ & $2,952,368,917$ & $328,654,401,280$ \\
\hline 27 & $325,702,032,362$ & $3,065,921,568$ & $328,767,953,930$ \\
\hline 28 & $325,702,032,362$ & $3,179,474,219$ & $328,881,506,581$ \\
\hline 29 & $325,702,032,362$ & $3,293,026,869$ & $328,995,059,232$ \\
\hline 30 & $325,702,032,362$ & $3,406,579,520$ & $329,108,611,882$ \\
\hline 31 & $325,702,032,362$ & $3,520,132,171$ & $329,222,164,533$ \\
\hline 32 & $325,702,032,362$ & $3,633,684,821$ & $329,335,717,184$ \\
\hline 33 & $325,702,032,362$ & $3,747,237,472$ & $329,449,269,834$ \\
\hline 34 & $325,702,032,362$ & $3,860,790,123$ & $329,562,822,485$ \\
\hline 35 & $325,702,032,362$ & $3,974,342,773$ & $329,676,375,136$ \\
\hline 36 & $325,702,032,362$ & $4,087,895,424$ & $329,789,927,786$ \\
\hline
\end{tabular}

Sumber : Data Olahan Penulis

Setiap responden diberikan penawaran yaitu masing-masing 1 unit apartemen untuk 1 variasi harga. Responden dapat menjawab seberapa besar minatnya atas tawaran tersebut. Hasil kuesioner disajikan dalam Tabel 5, 6, dan 7. Kemudian, untuk mendapatkan nilai permintaan pasar, jumlah unit yang menghasilkan permintaan tersebut masing-masing dikalikan dengan skala probabilitas yang telah ditentukan, yaitu: pasti membeli $=1$, ingin membeli $=0,75$, mungkin membeli $=0,5$, tidak ingin membeli $=0,25$, dan pasti tidak membeli $=0$.

Dengan demikian dapat dibuat kurva permintaan yang menggambarkan hubungan antara jumlah unit dengan harga yang ditawarkan. Dari kurva permintaan (Gambar 3, 4, dan 5) ditarik persamaan harga yang sesuai dengan persepsi pasar.

\section{Analisis Pendekatan Marginal}

Analisis pendekatan marginal adalah sebuah metode untuk mendapatkan kondisi dimana biaya marginal sama dengan penerimaan marginal. Biaya marginal (marginal cost) adalah penurunan dari total cost terhadap unit output dan penerimaan marginal (marginal revenue) adalah penurunan dari total 
revenue terhadap unit output. Total cost diketahui dari analisis pendekatan biaya, dan total revenue adalah hasil dari unit output apartemen dikalikan dengan besarnya nilai harga $\mathrm{P}$ didapatkan dari analisis pendekatan nilai permintaan. Kondisi yang diharapkan perusahaan adalah ketika setiap bertambahnya satu unit output menghasilkan tambahan penerimaan sama dengan biaya untuk memproduksinya. Sehingga dicari titik perpotongan persamaan garis MC dan MR. Setelah titik perpotongan antara persamaan MC dengan MR ditemukan, maka harga bisa dicari dengan memasukkan nilai perpotongan tersebut ke dalam persamaan permintaan $(\mathrm{P})$.

Tabel 5.

Hasil kuesioner unit $1 \mathrm{BR}$

\begin{tabular}{ccccccc}
\hline \hline $\begin{array}{c}\text { Harga unit } \\
\text { (Rp) }\end{array}$ & $\begin{array}{c}\text { Pasti } \\
\text { Dibeli }\end{array}$ & $\begin{array}{c}\text { Ingin } \\
\text { Dibeli }\end{array}$ & $\begin{array}{c}\text { Mungkin } \\
\text { Dibeli }\end{array}$ & $\begin{array}{c}\text { Tidak } \\
\text { ingin } \\
\text { Dibeli }\end{array}$ & $\begin{array}{c}\text { Pasti } \\
\text { tidak } \\
\text { Dibeli }\end{array}$ & $\begin{array}{c}\text { Jumlah } \\
\text { Unit }\end{array}$ \\
\hline 220000000 & 24 & 6 & 0 & 0 & 0 & 30 \\
240000000 & 16 & 5 & 3 & 2 & 4 & 30 \\
260000000 & 2 & 4 & 6 & 9 & 9 & 30 \\
280000000 & 1 & 1 & 3 & 7 & 18 & 30 \\
310000000 & 0 & 0 & 0 & 8 & 22 & 30 \\
330000000 & 0 & 0 & 0 & 0 & 30 & 30 \\
\hline \hline
\end{tabular}

Sumber : Data Olahan Penulis

Tabel 6.

Hasil kuesioner unit 2 BR

\begin{tabular}{ccccccc}
\hline \hline $\begin{array}{c}\text { Harga unit } \\
\text { (Rp) }\end{array}$ & $\begin{array}{c}\text { Pasti } \\
\text { Dibeli }\end{array}$ & $\begin{array}{c}\text { Ingin } \\
\text { Dibeli }\end{array}$ & $\begin{array}{c}\text { Mungkin } \\
\text { Dibeli }\end{array}$ & $\begin{array}{c}\text { Tidak } \\
\text { ingin } \\
\text { Dibeli }\end{array}$ & $\begin{array}{c}\text { Pasti } \\
\text { tidak } \\
\text { Dibeli }\end{array}$ & $\begin{array}{c}\text { Jumlah } \\
\text { Unit }\end{array}$ \\
\hline 360000000 & 21 & 6 & 2 & 0 & 1 & 30 \\
390000000 & 13 & 4 & 3 & 4 & 6 & 30 \\
410000000 & 9 & 2 & 4 & 4 & 11 & 30 \\
440000000 & 4 & 2 & 1 & 2 & 21 & 30 \\
470000000 & 2 & 1 & 2 & 1 & 24 & 30 \\
500000000 & 0 & 0 & 0 & 2 & 28 & 30 \\
\hline \hline
\end{tabular}

Sumber : Data Olahan Penulis

Tabel 7.

Hasil Kuesioner Unit 3 BR

\begin{tabular}{ccccccc}
\hline \hline $\begin{array}{c}\text { Harga unit } \\
(\text { Rp) }\end{array}$ & $\begin{array}{c}\text { Pasti } \\
\text { Dibeli }\end{array}$ & $\begin{array}{c}\text { Ingin } \\
\text { Dibeli }\end{array}$ & $\begin{array}{c}\text { Mungkin } \\
\text { Dibeli }\end{array}$ & $\begin{array}{c}\text { Tidak } \\
\text { ingin } \\
\text { Dibeli }\end{array}$ & $\begin{array}{c}\text { Pasti } \\
\text { tidak } \\
\text { Dibeli }\end{array}$ & $\begin{array}{c}\text { Jumlah } \\
\text { Unit }\end{array}$ \\
\hline 500000000 & 17 & 5 & 2 & 2 & 4 & 30 \\
540000000 & 10 & 4 & 4 & 4 & 8 & 30 \\
580000000 & 8 & 3 & 2 & 5 & 12 & 30 \\
620000000 & 6 & 4 & 1 & 1 & 18 & 30 \\
660000000 & 4 & 1 & 1 & 1 & 23 & 30 \\
700000000 & 0 & 0 & 0 & 0 & 30 & 30 \\
\hline \hline
\end{tabular}

Sumber : Data Olahan Penulis

\section{Penetapan harga unit $1 \mathrm{BR}$}

Biaya marginal (MC) adalah kemiringan kurva biaya total, yaitu setiap penambahan biaya untuk satu unit output yang diproduksi. Sesuai pada Tabel 5 besarnya Total Cost adalah $368,348,055,849$. Berdasarkan analisis dan perhitungan, berikut ini besarnya nilai TC dan MC unit $1 \mathrm{BR}$.

$\mathrm{TC}_{1}=279,126,477 \cdot 12 \mathrm{Q}$

$\mathrm{MC}_{1}=279,126,477.12$

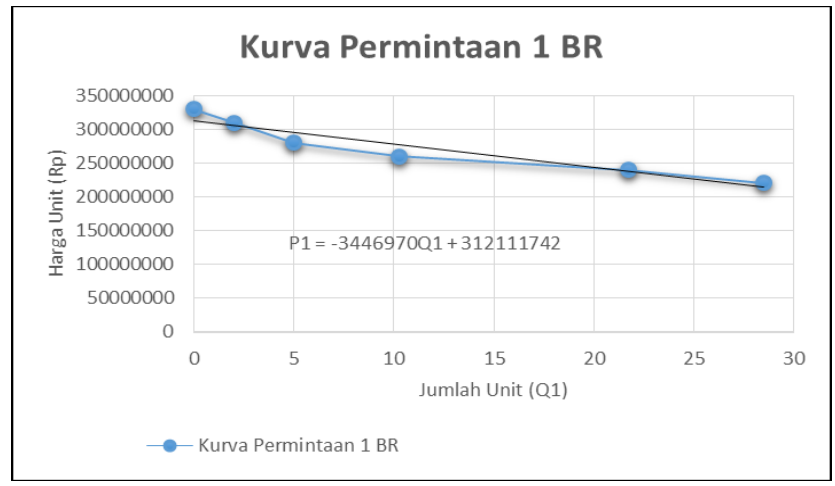

Gambar 3. Kurva Permintaan Unit 1 BR

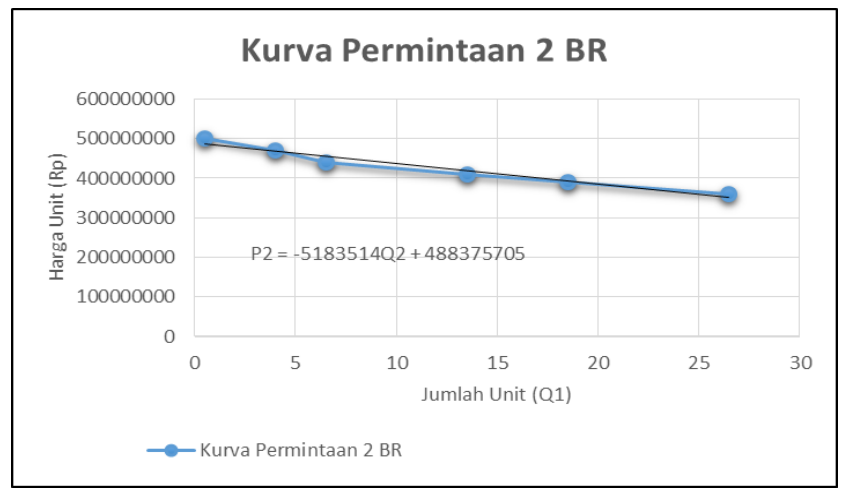

Gambar 4. Kurva Permintaan Unit 2 BR

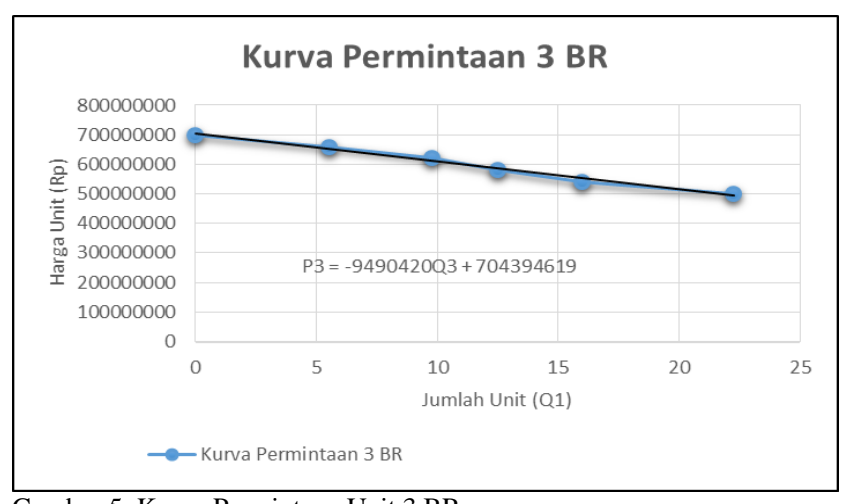

Gambar 5. Kurva Permintaan Unit 3 BR

Penerimaan marginal (MR) adalah penurunan dari total penerimaan (TR) terhadap unit output, yaitu:

$\mathrm{TR}=\mathrm{P} \times \mathrm{Q}$.

$P_{1}=-3,446,970 Q_{1}+312,111,742$

$\mathrm{TR}_{1}=\left(-3,446,970 Q_{1}+312,111,742\right) \times \mathrm{Q}_{1}$

$\mathrm{MR}_{1}=-6,893,940 Q_{1}+300568182$

Dengan menggunakan persamaan $\mathrm{MC}=\mathrm{MR}$, dapat diketahui titik perpotongan garisnya.

$$
\begin{aligned}
M C & =M R \\
279,126,477.12 & =-6,893,940 Q_{1}+300568182 \\
-6,893,940 Q_{1} & =279,126,477.12-300568182 \\
Q_{1} & =4.78
\end{aligned}
$$

Kemudian, harga dicari dengan memasukkan nilai Q1 ke dalam persamaan harga, yaitu

$\mathrm{P}_{1}=-3,446,970 Q_{1}+312,111,742$

$\mathrm{P}_{1}=295,619,109.56$ 
Jadi, harga berdasarkan analisis pendekatan marginal untuk apartemen tipe 1 BR adalah Rp 295,619,109.56,-

2. Penetapan harga unit $2 \mathrm{BR}$

Berdasarkan analisis dan perhitungan, berikut ini besarnya nilai TC dan $\mathrm{MC}$ unit $2 \mathrm{BR}$.

$\mathrm{TC}_{2}=359,514,902.53 \mathrm{Q}_{2}$

$\mathrm{MC}_{2}=359,514,902.53$

Penerimaan marginal (MR) adalah penurunan dari total penerimaan (TR) terhadap unit output, yaitu:

$\mathrm{TR}=\mathrm{P} \times \mathrm{Q}$.

$\mathrm{P}_{2}=-5,183,514 \mathrm{Q}_{2}+488,375,705$

$\mathrm{TR}_{2}=\left(-5,183,514 \mathrm{Q}_{2}+488,375,705\right) \times \mathrm{Q}_{2}$

$\mathrm{MR}_{2}=-10,367,028 Q_{2}+488,375,705$

Dengan menggunakan persamaan $\mathrm{MC}=\mathrm{MR}$, dapat diketahui titik perpotongan garisnya.

$$
\mathrm{MC}=\mathrm{MR}
$$

$$
\begin{aligned}
359,514,902.53 & =-10,367,028 Q_{2}+488,375,705 \\
-10,367,028 Q_{2} & =359,514,902.53-488,375,705 \\
Q_{2} & =12.43
\end{aligned}
$$

Kemudian, harga dicari dengan memasukkan nilai $\mathrm{Q}_{2}$ ke dalam persamaan harga, yaitu

$\mathrm{P}_{2}=-5,183,514 \mathrm{Q}_{2}+488,375,705$

$\mathrm{P}_{2}=423,945,303.77$

Jadi, harga berdasarkan analisis pendekatan marginal untuk apartemen tipe 2 BR adalah Rp 423,945,303.77,--

3. Penetapan harga unit $3 \mathrm{BR}$

Berdasarkan analisis dan perhitungan, berikut ini besarnya nilai TC dan MC unit 3 BR.

$\mathrm{TC}_{3}=619,386,228.58 Q$

$\mathrm{MC}_{3}=619,386,228.58$

Penerimaan marginal (MR) adalah penurunan dari total penerimaan (TR) terhadap unit output, yaitu:

$$
\begin{aligned}
\mathrm{TR} & =\mathrm{P} \times \mathrm{Q} . \\
\mathrm{P}_{3} & =-9,490,420 \mathrm{Q}_{3}+704,394,619 \\
\mathrm{TR}_{3} & =\left(-9,490,420 \mathrm{Q}_{3}+704,394,619\right) \times \mathrm{Q}_{3} \\
\mathrm{MR}_{3} & =-18,980,840 Q_{3}+704,394,619
\end{aligned}
$$

Dengan menggunakan persamaan $\mathrm{MC}=\mathrm{MR}$, dapat diketahui titik perpotongan garisnya.

$$
\begin{aligned}
\mathrm{MC} & =\mathrm{MR} \\
619,386,228.58 & =-18,980,840 Q_{3}+704,394,619 \\
-18,980,840 Q_{3} & =619,386,228.58-704,394,619 \\
Q_{3} & =4.47
\end{aligned}
$$

Kemudian, harga dicari dengan memasukkan nilai $\mathrm{Q}_{3}$ ke dalam persamaan harga, yaitu

$\mathrm{P}_{3}=-9,490,420 \mathrm{Q}_{3}+704,394,619$

$\mathrm{P}_{3}=661,890,423.79$

Jadi, harga berdasarkan analisis pendekatan marginal untuk apartemen tipe 3 BR adalah Rp 661,890,423.79,--

\section{KESIMPULAN}

Berdasarkan analisis yang telah dilakukan, didapatkan harga jual untuk tiap unit apartemen Puncak Dharmahusada, yaitu; tipe 1 BR Rp Rp 295,619,109.56,-, tipe 2 BR Rp $423,945,303.77,-$, dan tipe 3 BR Rp 661,890,423.79,-.

\section{DAFTAR PUSTAKA}

[1] Aprilia, W. I., dan Utomo, C. 2014. "Analisis Penetapan Harga Jual Unit Apartemen Bale Hinggil di Surabaya”. Jurnal Teknik POMITS vol. 3 No.2 D:59-64.

[2] Hanundyasari, D.R. dan Utomo, C. 2014. "Analisa Penetapan Harga Pokok Penjualan Apartemen Puri Park View Tower E Kebon Jeruk Jakarta Barat”. Jurnal Teknik POMITS vol. 3 No.2 D:147 - 152.

[3] Hidayat, M.F dan Utomo, C. 2014. "Analisa Penetapan Harga Jual Unit Rumah di Perumahan Griya Agung Permata, Lamongan”. Jurnal Teknik POMITS vol. 3 No. 2 C:57- 61.

[4] Fahad dan Utomo, C. 2013. "Analisa Penetapan Harga Jual Unit Rumah Pada Proyek Perumahan Soka Park Bangkalan". Jurnal Teknik POMITS vol. 2 No.2 C:173-177.

[5] Darmayanti, R., dan Utomo, C. 2014. “Analisa Biaya Dan Permintaan Pada Penetapan Harga Marginal Unit Rumah Di Perumahan Royal Regency, Lumajang"'. Jurnal Teknik POMITS vol. 3 No.1 D:36-40.

[6] Wahyudhi, O., dan Utomo, C. 2014. "Analisis Investasi Pada Proyek Pembangunan Apartemen Bale Hinggil Surabaya". Jurnal Teknik POMITS Vol. 3 No.2 D:41-46.

[7] Amstrong, G., dan Kotler, P. 2008. Prinsip-prinsip Pemasaran, Edisi ke12. Jakarta: Erlangga.

[8] Kotler, P. 2002. Manajemen Pemasaran. Jakarta: Prenhallindo

[9] Hirshleifer, P., dan Glazer, A., dan Hirshleifer, D. 2005. Price Theory and Applications. New York: Cambridge University Press.

[10] Juwana, J. S. 2005. Panduan System Bangunan Tinggi: Untuk Arsitek Dan Praktisi Bangunan. Jakarta: Erlangga. 